\title{
Effect of curing modes on the depth of cure of resin composite
}

Abdul-Adheem R Al-Mallah BDS, MSc (Assist Lect)

\author{
Department of Conservative Dentistry \\ College of Dentistry, University of Mosul
}

\begin{abstract}
Aims: To study the effect of different curing modes of Light emitting diodes (LED) curing unit on the depth of cure (DOC) of composite resin with light and dark shades and compare the results with conventional curing method by the use of halogen curing light. Materials and Methods: A total of 40 cylindrical composite resin samples (4mm diameter and $6 \mathrm{~mm}$ height) were prepared, 20 of light shade and 20 of dark shade. They were subjected to four curing modes $(\mathrm{n}=5$ for each group): conventional halogen light, and three modes related to the LED light curing unit (LCU) which were: Fast (F); Ramped $(\mathrm{R})$; and Pulsed $(\mathrm{P})$. The samples were irradiated to the time required by the manufacturer for each curing mode, and a digital micrometer was used to measure the depth of cure according to scraping method described in ISO 4049:2000. Data were collected and analyzed for comparison. Results: No significant difference was found in the DOC of composite irradiated by LED curing light for all of the three curing modes or shade. However, the LED produced significantly greater depths of cure when compared with conventional halogen curing unit for both shades. The lighter shade was cured to a significantly greater depth than dark one when considering halogen LCU. Conclusions: All curing modes of the LED light can produce similar DOC regardless of composite shade when irradiated to the time recommended by the manufacturer. However, Curing with conventional halogen curing unit yielded the least DOC values for light or dark shades when compared with LED units. Longer irradiation times are needed to cure dark shades by the use of halogen LCUs.
\end{abstract}

Key Words: Curing depth, light emitting diode, resin composite

Al-Mallah AR. Effect of curing modes on the depth of cure of resin composite. Al-Rafidain Dent $J$. 2007; 7(2): 195-200.

Received: 24/7/2006 Sent to Referees: 26/7/2006

Accepted for Publication: 25/9/2006

\section{INTRODUCTION}

Curing of dental composites with blue light was introduced in the 1970 s. $^{(1)}$ The source of blue light is normally a halogen bulb combined with a filter, so that blue light in the $410 \mathrm{~nm}-500 \mathrm{~nm}$ region of the visible spectrum is produced. Light in this range of wavelengths is the most effectively absorbed by the camphorquinone photoinitiator ${ }^{(2)}$ that is present in the resin component of light activated dental composites.

Although halogen bulb based light curing units (LCUs) are most commonly used to cure dental composites, this technology has inherent drawbacks. Halogen bulbs have a limited effective lifetime of around 50 hours. ${ }^{(3)}$ The bulb, reflector and filter degrade over time due to the high temperatures produced, leading to a reduction in light output. The result is a reduction of the LCU's effectiveness to cure dental composites. ${ }^{(4)}$ The cli- nical implication of this for the dentist is a negative effect on the physical properties of composites with an increased risk of premature failure of restorations. ${ }^{(5)}$

As the number of resin-based composite restorations placed by dentists each day increases, it is becoming more impotant to devise new ways of decreasing the curing time and reducing marginal gaps caused by polymerization shrinkage. Recently, resin-based composite curing lights have been developed that have higher intensities and shorter curing cycles which help speed resin- based composite curing. ${ }^{(6)}$

Light emitting diodes (LEDs), such as those encountered as indicators in car dashboards, have lifetimes of over 10,000 hours and undergo little degradation of light output over this time, a distinct advantage when compared with halogen bulbs. ${ }^{(7)}$ The 
innovateive LED technology, based on semiconductors, opened new and interesting views in the field of photopolymerization; to the advantages of a soft-start polymerrization they add the safety, efficiency, economy and long lifetime of LED light. ${ }^{(8)}$ Ramped- and stepped-intensity curing lights are marketed for their ability to "softstart" polymerization. This creates less stress at the resin-based composite-enamel/dentin joint and, thus, reduces marginal gaps in resin-based composite restorations. ${ }^{(9)}$ These curing lights first use a lower-intensity light followed by high-intensity light. There is limited information, however, regarding these curing lights and their effect on microleakage and curing depth for different categories of resin-based composite materials. ${ }^{62}$

The aim of the present study was to compare the effect of different curing modes of the LED curing light on resin composite depth of cure using light and dark shades and compare the results with the conventional halogen curing light.

\section{MATERIALS AND METHODS}

The composite resin used in this study was Tetric (Vivadent Dental Gmbh, Germany) with light shade (A1) and dark shade (A3.5). The LCUs used were a conventional halogen curing unit ( Quayle Dental, England ) as the control, and an LED curing unit ( Top light, Taiwan )(Figure 1). The latter has three different modes of cure: Fast (F); Ramped (R); and Pulsed (P). The F mode uses a full intensity light; while $\mathrm{R}$ mode uses low intensity light (for 2 seconds) at first followed by full intensity; and the P mode uses intermittent intervals of rest (no light) for 0.2 seconds followed by full intensity light for 0.8 seconds. The light intensity for the halogen and LED LCUs were measured using a radiometer (Cromatest 7041, Mega-physik, Germany).

For specimen preparation, a $6 \mathrm{~mm}$ thick acrylic block was used. A hole with $5 \mathrm{~mm}$ diameter was cut into the block (Figure 2), then the block placed on a glass slab and a black vinyl sleeve with a $4-\mathrm{mm}$ lumen diameter was inserted inside the hole and cut to the appropriate height (Figure $3)$.

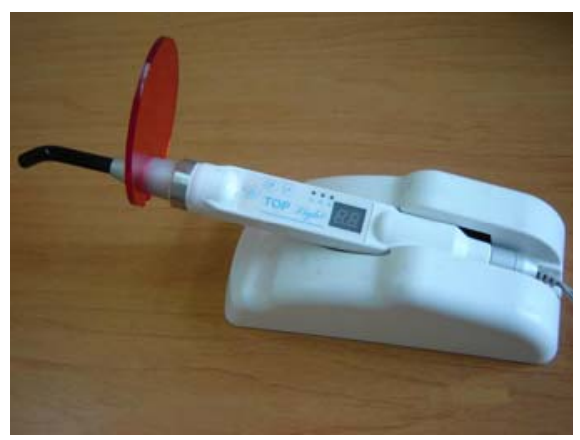

Figure (1): LED light curing unit

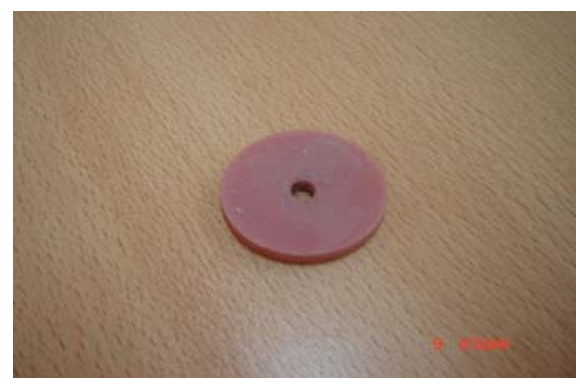

Figure (2): Acrylic mold with a hole

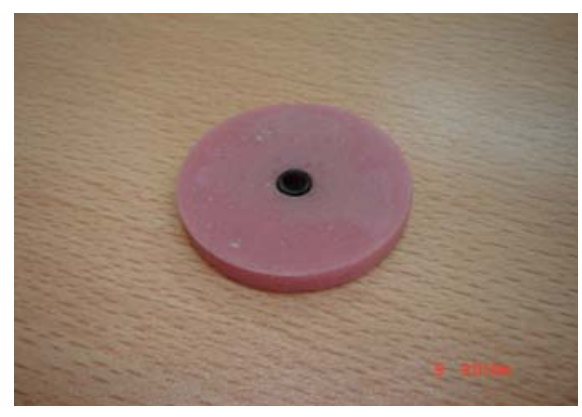

Figure (3): Black vinyl sleeve in place.

The resin-based composite was placed inside the vinyl sleeve using plastic spatula and a glass slide placed on top of the resin-based composite. The curing light tip was placed directly on top of the glass slide ${ }^{(6)}$ (Figure 4).

Curing the resin composite was performed according to the recommended curing time by the manufacturer (40 second).

After polymerization, the vinyl sleeve was removed from the acrylic block and sec-tioned (Figure 5) to remove all of the soft, uncured resin-based composite material from the bottom of the resin-based composite plug using a plastic spatula. Then, the height of the cured resin-based composite plug was measured using a digital micrometer which was accurate to 0.01 $\mathrm{mm}$ (Figure 6), and di-vided this value by 2. 


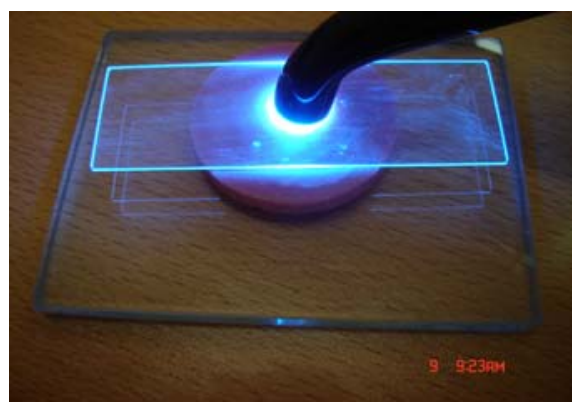

Figure (4): Curing composite samples

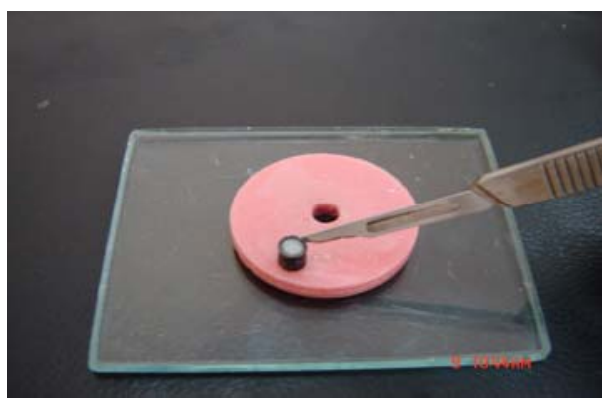

Figure (5): Sectioning vinyle sleeve.

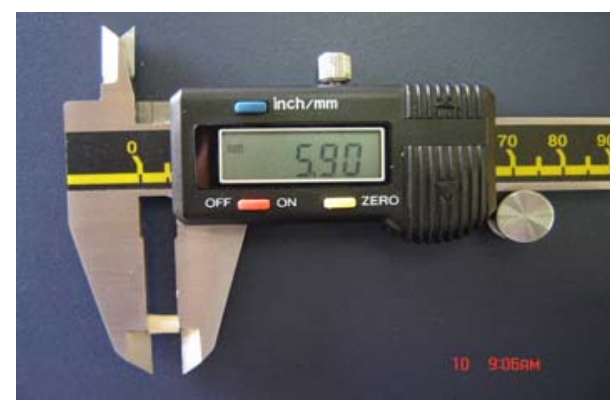

Figure (6): Digital micrometer

Five samples were used for each mode of cure. ${ }^{(10)}$ The depth of cure was measured according to scraping method described in ISO 4049:2000. ${ }^{(11)}$ The ISO defines depth of cure as 50 percent of the length of the comp-osite specimen after the uncured material is removed with a plastic spatula. $^{(11)}$

One way analysis of variance (ANOVA) and Student's t-test were used to compare the results obtained between the groups.

\section{RESULTS AND DISCUSSION}

The light intensities for both curing units are listed in Table (1). The results of the depth of cure for shades A1 and A3.5 using the three modes of LED LCU (F, R, $\mathrm{P})$ are presented in Table (2) and their one way analysis of variance are listed in Table (3).
Table (1): Light intensities of the curing

\begin{tabular}{ccc}
\multicolumn{2}{c}{ units. } \\
\hline \multicolumn{2}{c}{ LCU } & Intensity $\left(\mathbf{m W} / \mathbf{c m}^{2}\right)$ \\
\hline Halogen & 340 \\
& $\mathbf{F}$ & 275 \\
LED & $\mathbf{R}$ & $12 / 275^{*}$ \\
& $\mathbf{P}$ & 280 \\
\hline
\end{tabular}

F: fast; R: Ramped; P: Pulsed; *: Start at $12 \mathrm{~mW} / \mathrm{cm}^{2}$ for 2 seconds followed by full intensity.

Those results revealed that there was no significant difference in the DOC between curing modes for both shades. This result was in agreement with Yap et al., ${ }^{(12)}$ who reported that curing mode did not significantly affect the DOC for the resin-based composite. However, Obici et al., ${ }^{(13)}$ demonstrated that the DOC was strongly affected by Photoactivation method, with the intermittent light producing the highest DOC and was statistically different from continuous and exponential light. In this study, the irradiation time was fixed to 40 seconds, (as the aims of this study were directed toward evaluating the effect of curing mode, and not the exposure time, on the DOC). This time was specified by the manufacturer for the halogen and not the LED LCUs. Since the LED lights have higher irradiance in the region of peak absorption of camphorquinone photoinitiator present in most light activated composite ${ }^{(14)}$, and since the increase in the exposure time can lead to significantly higher DOC ${ }^{(15)}$, this could explain the results obtained in this study that no significant difference was observed in DOC between curing modes when exposure time was fixed to 40seconds.

When each LED curing mode of shade A1 was compared with it's synonymous of shade A3.5 (Figure 7), no significant difference in the DOC was obtained between both shades using the same mode. This was in agreement with Hackman et al., ${ }^{(16)}$ who concluded that no significant difference was present between light and dark shades of the same composite with respect to DOC. This result disagree with Fan et al., ${ }^{(10)}$ who found that shade A1 provided greater depth of cure than shade A3.5 of the same composite. 
Table (2): Depth of cure for light emitting diode curing modes

\begin{tabular}{ccccc}
\hline \multirow{2}{*}{ Shade } & Curing mode & N & depth of cure & \multirow{2}{*}{ Significance } \\
\cline { 4 - 5 } & $\mathbf{F}$ & 5 & $2.971 \pm 0.0309$ & \\
A1 & $\mathbf{R}$ & 5 & $2.927 \pm 0.0421$ & Not Significant \\
& $\mathbf{P}$ & 5 & $2.945 \pm 0.0278$ & \\
\hline \multirow{3}{*}{ A3.5 } & $\mathbf{F}$ & 5 & $2.921 \pm 0.0484$ & \\
& $\mathbf{R}$ & 5 & $2.946 \pm 0.0391$ & Not Significant \\
& $\mathbf{P}$ & 5 & $2.943 \pm 0.0220$ & \\
\hline
\end{tabular}

F: fast; R: Ramped; P: Pulsed; N: Number of samples.

Table (3): Analysis of variance of depth of cure for A1 and A 3.5 shade

\begin{tabular}{ccccccc}
\hline Shade & Source & df & SS & MS & F-value & $\boldsymbol{P}$-value \\
\hline \multirow{4}{*}{ A1 } & Source of variance & 2 & 0.00489 & 0.00245 & & \\
& Error & 12 & 0.01400 & 0.00117 & 2.10 & 0.166 \\
& Total & 14 & 0.01889 & & & \\
\hline \multirow{3}{*}{ A3.5 } & Source of variance & 2 & 0.00186 & 0.00093 & & \\
& Error & 12 & 0.01742 & 0.00145 & 0.64 & 0.543 \\
& Total & 14 & 0.01928 & & & \\
\hline
\end{tabular}

df: Degree of freedom; SS: Sum of square; MS: Mean of square

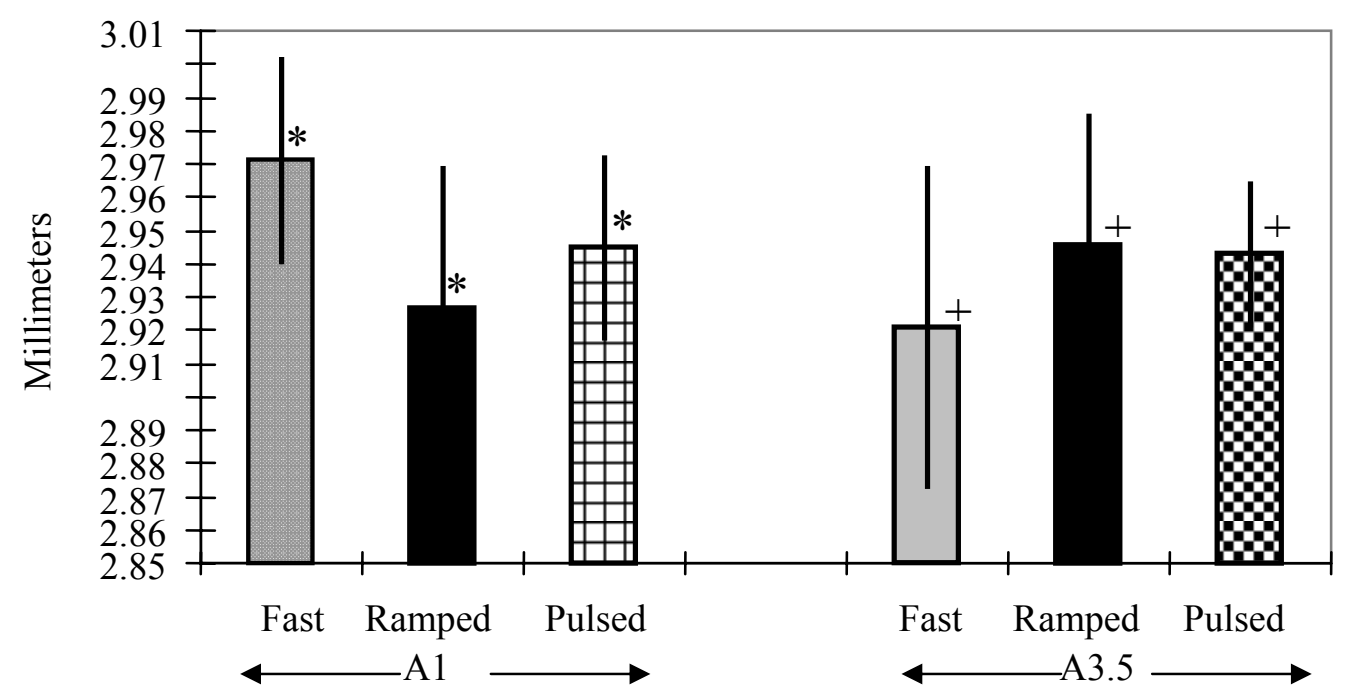

Figure (7): Mean depth of cure for light emitting diode curing modes.

* No significant difference among shade A1 groups ( $p>0.05) ;+$ No significant difference among shade A3.5 groups $(p>0.05)$.

Table (4) represented a comparison for DOC between LED and halogen LCUs for both shades. The LED was able to produce significantly greater depth of cure values than those produced by conventional halogen light and for both shades. The effect of shade on the DOC was evident in this compareison since the results for shade A1 were significant at $\mathrm{P} \leq 0.01$, while for shade A3.5 were significant at $\mathrm{P} \leq 0.001$. This result was in agreement with Mills et al., ${ }^{(5)}$ and Uhl et al., ${ }^{(17)}$ who concluded that LED LCUs achieved significantly greater DOC than halogen units. Shortall ${ }^{(18)}$ stated that the LED LCUs were able to cure the same depth of resin composite in half the time when compared with halogen units. This can be explained by that the peak of absorption spectrum of the camphorquinone photoinitiator is within the wavelength region from 400 to $500 \mathrm{~nm}^{\left({ }^{(19)}\right.}$ The most effective wavelength to activate ploymeri- 
zation of the materials is $470 \mathrm{~nm}$, and the most effective wavelength band is in the range $450-490 \mathrm{~nm} .^{(19)}$ The spectral output of LED units falls conveniently within this most effective wavelength range. ${ }^{(14)}$ This may account for the greater DOC observed for samples cured with LED units. ${ }^{(5)}$ Those results disagree with other studies ${ }^{(13,20,21)}$ who found that conventional halogen
LCUs produced greater DOC than LED. This can be ascribed either to the low intensity, or the absence of heat emission from LED units. Heat is emitted from halogen LCUs and this may increase the mobility of the monomer, increasing the probability of the occurrence of conversion ${ }^{(13)}$, and conesquently, greater depths of cure.

Table (4): Comparison for depth of cure between LED and halogen LCU

\begin{tabular}{lllllll}
\hline \multirow{2}{*}{ Curing mode } & \multicolumn{2}{l}{ depth of Cure } & \multirow{2}{*}{ T-value } & $\boldsymbol{P}$-value & DF & significance \\
\cline { 2 - 6 } & Mean \pm SD (mm) & & & & \\
\hline LED A1 & $2.971 \pm 0.0309$ & 3.59 & 0.0071 & 8 & $\mathrm{~S}^{*}$ \\
Halogen A1 & $2.770 \pm 0.121$ & 9.78 & 0.0000 & 8 & $\mathrm{~S}$ \\
LED A3.5 & $2.921 \pm 0.0484$ & &
\end{tabular}

* Significant at $\mathrm{P} \leq 0.01$; ** Significant at $\mathrm{P} \leq 0.001$

There was a statistically significant difference in the DOC between both shades when cured with conventional halogen LCU (Figure 8). The light shade was cured to a greater depth than the dark one. This reduceed DOC may be due to that the shade pigments used in composite product may act to filter the light and provide less DOC compared with light shades. ${ }^{(22)}$ This is in agreement with Kamel ${ }^{(22)}$; Pollack and Lewis ${ }^{(23)}$ who found that the dark shades of resin composite tested showed less cure depths than the lighter ones.

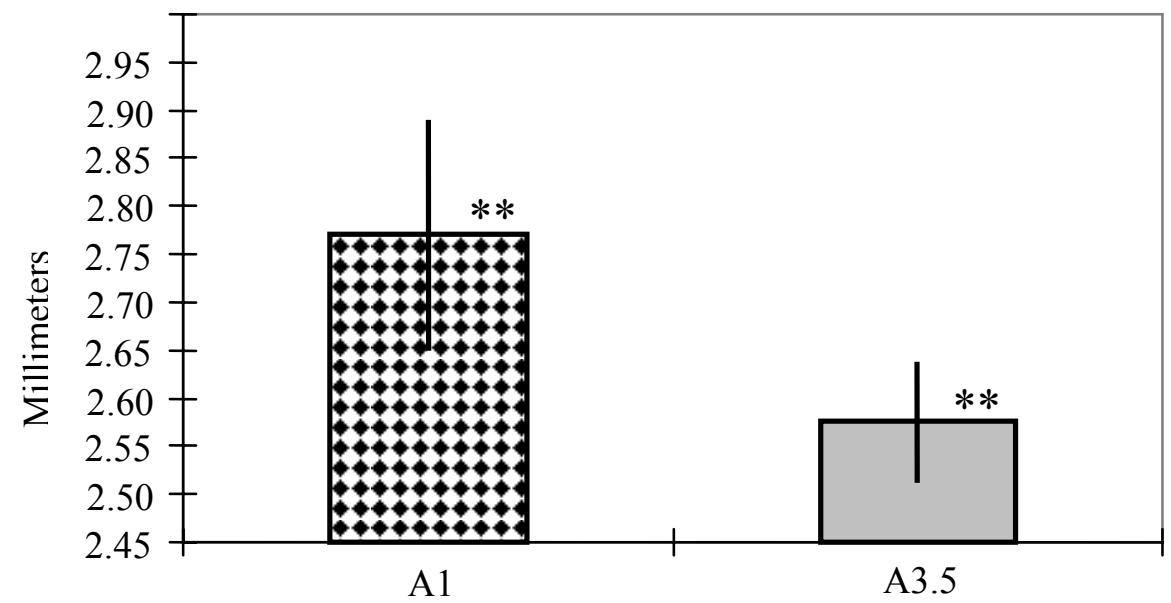

Figure (8): Mean depth of cure for both shades with halogen light curing unit. ** Significant difference between two groups $(p \leq 0.05)$.

\section{CONCLUSIONS}

This study revealed that there was no effect of LED curing mode on the depth of cure of resin composite with different shades. The LED LCU produced greater depth of cure than the halogen curing light regardless of shade. The halogen unit cured the light shade of composite to significantly greater depths than the dark one, unlike the LED where there was no effect of shade on curing depth.

\section{REFERENCES}

1. Bassiouny MA, Grant AA. A visible lightcured composite restorative. Br Dent $\mathrm{J}$. 1978; 145: 327-330.

2. Cook WD. Spectral distribution of dental photopolymerization sources. J Dent Res. 
1982; 61: 1436-1438.

3. Cayless MA, Marsden AM. Tungsten halogen lamps. In Lamps and Lighting. $3^{\text {rd }}$ ed. London. Edward Arnold Ltd. 1983; Pp: 169-182.

4. Barghi N, Berry T, Hatton C. Evaluating intensity output of curing lights in private dental offices. J Am Dent Assoc. 1994; 25 : 992-996.

5. Mills RW, Jandt KD, Ashworth SH. Dental composite depth of cure with halogen and blue light emitting diode technology. Br Dent J. 1999; 186: 388-391.

6. Jain $p$, Pershing A. Depth of cure and microleakage with high-intensity and ramped resin-based composite curing lights. $J \mathrm{Am}$ Dent Assoc. 2003; 134: 1215-1223.

7. Haitz RH, Craford MG, Weissman RH. Light Emitting Diodes. In Bass M (ed) Handbook of optics. $2^{\text {nd }}$ ed. McGraw Hill Inc. 1995.

8. La Torre G, Marigo L, Pascarella GA, Rumi G. Light-emitting diodes (LED) technology applied to the photopolymerization of resin composites. Minerva Stomatol. 2003; 52: 193-200.

9. Burgess JO, DeGoes M, Walker R, Ripps AH. An evaluation of four light-curing units comparing soft and hard curing. Pract Periodontics Aesthet Dent. 1999;11: 125-132.

10. Fan PL, Schumacher RM, Azzolin K, Geary R, Eichmiller FC. Curing-light intensity and depth of cure of resin-based composites tested according to international standards. J Am Dent Assoc. 2002; 133: 429434.

11. International Organization for Standardization. ISO 4049:2000. Dentistry-polymer-based filling, restorative and luting materialls. $3^{\text {rd }}$ ed. Geneva, Switzerland: International Organization for Standardization; 2000.

12. Yap AU, Ng SC, Siow KS. Soft-start polymerization: influence of effectiveness of cure and post-gel shrinkage. Oper Dent. 2001; 26: 260-266.
13. Obici AC, Sinhoreti MAC, Correr Sobrinho L, de Goes MF, Consani S. Evaluation of depth of cure and knoop hardness in a dental composite photo-activated using different methods. Braz Dent $J$. 2004; 15: 199-203.

14. Nomoto R, McCabe JF, Hirano S. Comparis on of halogen, plasma and LED curing units. Oper dent. 2004;29: 287-294.

15. Lindberg A, Peutzfeldt A, van Dijken JW. Effect of power density of curing unit, exposure duration, and light guide distance on composite depth of cure. Clin Oral Investig. 2005; 9: 71-76.

16. Hackman ST, Pohjola RM, Rueggeberg FA. Depths of cure and effect of shade using pulse-delay and continuous exposure photo-curing techniques. Oper Dent. 2002; 27: 593-599.

17. Uhl A, Sigusch BW, Jandt KD. Second generation LEDs for the polymerization of oral biomaterials. Dent Mater. 2004; 20: 80-87.

18. Shortall AC. How light source and product shade influence cure depth for a contemporary composite. J Oral Rehabil. 2005; 32: 906-911.

19. Nomoto R. Effect of light wavelength on polymerization of light cured resins. Dent Mater J. 1997;16: 60-73.

20. Tsai PC, Meyers IA, Walsh LJ. Depth of cure and surface micro hardness of composite resin cured with blue LED curing lights. Dent Mater. 2004; 20: 364-369.

21. Aravamudhan K, Floyd CJE, Rakawski D, Flaim G, Dickens SH, Eichmiller FC, Fan PL. Light emitting diode curing light irradiance and polymerization of resin based composite. J Am Dent Assoc. 2006; 137: 213-223.

22. Kamel JH. The effect of composition and shade on the polymerization of light cured composite resin. Iraqi Dent J. 1998; 23: 247-253.

23. Pollack B, Lewis AL. Visible light curing generation. Can Dent. 1981; 29: 488 